\title{
The technology of formation of future teachers' information culture
}

\author{
L.I. Abbasova ${ }^{1 *}$, I.V. Zotova ${ }^{2}$, and Z.I. Mustafaeva ${ }^{3}$ \\ ${ }^{1}$ State Budget Educational Institution of Higher Education of the Republic of Crimea Crimean \\ Engineering and Pedagogical University the name of FevziYakubov, Simferopol, Russia \\ 2 State Budget Educational Institution of Higher Education of the Republic of Crimea Crimean \\ Engineering and Pedagogical University the name of FevziYakubov, Simferopol, Russia \\ ${ }^{3}$ State Budget Educational Institution of Higher Education of the Republic of Crimea Crimean \\ Engineering and Pedagogical University the name of FevziYakubov, Simferopol, Russia
}

\begin{abstract}
The article describes features of the formation of future teachers' information culture. The relevance of the development, implementation and maintenance of the technology of forming process of information culture of future teachers is substantiated. Different views of scientists on the definitions of "information culture of a person", "technology" are considered. The main components of information culture are highlighted: computer literacy, information competence, information reflection, information culture creation. The constituent elements of pedagogical technology are listed, which is represented by a set of goals and methods aimed at implementing the projected learning process and is presented by a phased implementation plan. The main characteristics of a technology for the formation of information culture of a future educator are revealed and disclosed. The article describes the results of experimental work to identify the current level of formation of information culture of future teachers. Comparative results of the data obtained during the control experiment testify to the effectiveness of the probed technology and the readiness to use information technologies in professional activities.
\end{abstract}

\section{A problem statement}

At the present stage of the development of society, in the conditions of reforming and improving the system of higher pedagogical education in Russia, it becomes necessary to actively search for new reserves of high-quality training of specialists capable of developed professional improvement in accordance with the requirements of a specific professional orientation.

The processes of informatization taking place in modern society have an impact on the professional training of specialists, thereby actualizing the problem of forming the information culture of future teachers. The formation of information culture of future teachers requires the development of a specific technology as well as theoretical

\footnotetext{
* Corresponding author: prof-ped.gpa@mail.ru
} 
substantiation of the means of implementing this technology in the educational process of a higher educational organization.

The need to develop such a technology and the relevance of its implementation in the educational process of a higher educational organization is determined by a number of external processes that occur in society and affect the professional training of specialists. This is an awareness of the fundamental role of information in society, a colossal increase in the volume of information, the development of information technologies, the formation of an information community and information culture.

\subsection{The objective of the work}

The concept of "information culture" is interpreted in different ways in advanced pedagogical research works. T.P. Gordienko and N.V. Gorbunova [1] in their writings revealed the concept of "information culture of a personality" as a set of rules for human behavior in an information society, means and norms of communication with artificial intelligence systems, conducting a man-machine dialogue in systems of "hybrid intelligence", introduction of telematics, global and local information networks. This concept includes the ability of a person to think over and assimilate the informational picture of the world as a system of signs and symbols, direct and reverse information networks, freely navigate in the information society and adapt to it. The formation of the information culture of the individual is realized, first of all, in the process of studying computer science and information technologies in educational organizations and the involvement of modern electronic means of transmitting information in the educational process.

A sufficiently detailed analysis of information culture is presented in the works of R.Yu. Hurum [2], A.A. Pankova [3], V.A. Skakunova [4], E.A. Koshevaya [5], N. Gendina [6], BiyuanXie [7]. The authors analyze the information culture of an individual as the ability and needs of a specialist to use available information opportunities for a systematic and meaningful search for new knowledge, its interpretation and dissemination. According to V.V. Klinov [8], O.V. Sizova [9], Mimi Li [10], B.L. Dey [11], K. Patton [12], the key components of an individual's information culture are the ability to choose and express goals, set goals, build information processes and phenomena that are studied to analyze information models with the support of automated information systems and interpret the results; predict the results of decisions made and make accompanying inferences; apply artificial intelligence systems, as well as other modern information technologies, to analyze processes and phenomena. At the same time, the relevant skills are ordering, systematization, structuring of data and knowledge, understanding the essence of information modeling, methods of presenting data and knowledge.

Based on the research works of L.A. Lisavol [13], G.S. Vyalikova [14], A.A. Komarova [15], E.P. Tatyanina [16], K.S. Aibatyrov [17], we distinguish the following elements of information culture: computer literacy, information competence, information reflection, information culture creation.

Information culture of a teacher is a systematic characteristics of a teacher in the pedagogical direction of training, which is a qualitative characteristics of his information activity, its goals, means, results, which are expressed in a set of knowledge, skills and abilities, motivational attitudes in working with information sources and allowing the teacher to effectively participate in all types of work with information - obtaining, accumulating, coding and processing of any kind, in the creation on this basis of qualitatively new information, its transmission, practical use. 


\section{Results of the research}

By the formation of information culture we mean the process of personality transformation, determined by the interaction of specially created internal factors and external conditions, which is aimed at mastering methods of cognition, interaction, relationships, information activities, the development of an information lifestyle, and the activity of working with information as a cultural object.

Considering the definition of the concept of pedagogical technology, it should include the following positions:

- goal setting should be focused on the final result;

- educational process must represent the algorithm of actions of the participants;

- monitoring should be carried out to compare planned and acquired results;

- technology adjustment should be done at any stage.

The development and use of pedagogical technologies in the educational process of higher educational organizations contributes to the planning of a teacher's work, setting goals and determining the trajectory of formation, that is, the management of the learning process. The use of pedagogical technology will allow you to be directed to the result in conditions of validity. Pedagogical technology must be viewed as a systematic and consistent practical implementation of the designed learning process, a system of methods and goals.

Consequently, the development of the definition of pedagogical technology is rooted in the past century, in connection with which there are many scientific works that describe the features of the development, structure, content, principles of the implementation of pedagogical technology. When developing a technology for the formation of information culture of a future educator, we will rely on the scientific research of famous teachers, such as: Shiang-Kwei Wang [18], B.S. Haug [19], M.L. Gruzdeva [20], G.S. Vyalikov [21]. The technology of forming information culture of a future educator is developed on the basis of three characteristics: 1) goal-setting; 2) meaningful; 3) organizational and in accordance with the widespread formula: "PT (pedagogical technology) = goals + objectives + content + methods + forms of education".

The goal-setting characteristic of the technology of forming information culture of a future teacher contains the goal and objectives. Separations of goals by importance, timing of implementation is significant. The content characteristics is a description of the content with a justification of feasibility, focus and duration in terms of the implementation time. The organizational characteristics of the technology reflects the implementation of the selected organizational and pedagogical conditions through the choice of appropriate methods, forms, means and methods of influence.

A purpose-setting characteristic of the technology of forming information culture of a future educator is presented as follows. The concept of a "goal" in encyclopedic dictionaries: ideal mental anticipation of the result of activity; a presented or desired event; image of a future result. The purpose of our technology for the formation of information culture of a future educator is to give an idea of the dialogic nature, variability, openness of knowledge. The stated goal consists of pedagogical tasks. For example, the first goal of technology is the formation of initial information knowledge. Dividing it into smaller parts involves solving the following tasks: mastering elementary knowledge about modern technologies; knowledge of the rules of the information society; the ability to search for the necessary information; the ability to handle software and hardware, read elementary device instructions. Thus, the goal-setting characteristic of the technology of forming information culture of a future educator contains the goals and objectives of each stage; their relationship and sequence are indicated.

The content of the technology for the formation of information culture of a future teacher was developed based on: psychological mechanisms of the formation of information culture; provisions of the "concept of regulation of social behavior" by M.V. 
Popov [22]. In accordance with the provisions of this concept, attitudes and value orientations are hierarchically subordinate to each other. At the first level, there are attitudes aimed at satisfying vital needs that do not carry awareness. At the second level, there are attitudes determined by the social needs of the individual. At the third level, there are social attitudes that regulate social activity and interests. The fourth level is the system of personal value orientations. The given grounds for developing the technology of forming information culture of a future teacher are in good agreement, determine the direction of the content, mechanisms and means.

At the first stage, students adapt to the information society. At the second stage, future teachers master various capabilities of information technology. At the third stage, the development of motivational structures of the individual is carried out in the process of mastering information knowledge and on the basis of the emergence of social attitudes towards the information society. At the fourth stage, the formation of an individual value system for future educators is completed. For example, at this stage, the project method can be applied, which is aimed at an independent search for information, its creative interpretation, reflecting the personal attitude of the author.

The organizational characteristic of the technology is the creation of special conditions that contribute to the successful implementation and increase in efficiency.

Criteria, indicators and levels of formation of information culture of future teachers are the following: motivational-value criterion with indicators (level of formation of socially significant motives, assimilation of norms and rules of information activity, flexibility and variety of criteria for assessing information phenomena from the point of view of social significance); cognitive criterion with indicators (the level of formation of information style of thinking, the level of knowledge about oneself, one's strengths and weaknesses, ways of using and compensating them); activity criterion (possession of methods and means of information activity and communication, the degree of assimilation and operation of healthsaving technologies in working with information).

The formation of information culture of a future educator as a personality trait, which manifests itself in the implementation of universal methods of cognition, activity in the information environment and determines the readiness of the individual for an informational way of life, activities for the creation, preservation, processing, dissemination of information as an object of culture.

The data obtained on the ascertaining and control stages of the experimental work are presented in the summary table 1.

Table 1. The general level of formation of information culture of future teachers (in\%).

\begin{tabular}{|l|c|c|c|c|}
\hline \multirow{2}{*}{ Groups } & \multicolumn{2}{|c|}{ Experimental group } & \multicolumn{2}{c|}{ Control group } \\
\cline { 2 - 5 } Levels & $\begin{array}{c}\text { at the } \\
\text { beginning of } \\
\text { exp. }\end{array}$ & $\begin{array}{c}\text { After formative } \\
\text { exp. }\end{array}$ & $\begin{array}{c}\text { at the } \\
\text { beginning of } \\
\text { exp. }\end{array}$ & $\begin{array}{c}\text { After formative } \\
\text { exp. }\end{array}$ \\
\hline High & 11.77 & 29.4 & 10.72 & 12.59 \\
\hline Medium & 57.19 & 60.35 & 57.33 & 58.94 \\
\hline Low & 31.04 & 10.25 & 31.95 & 28.47 \\
\hline
\end{tabular}

The data shown in the table demonstrate that after the formative stage of the experiment, the percentage of students who achieved a high level of information culture of respondents after the formative experiment increased significantly compared to the results of the initial diagnosis in both the experimental and control groups.

A comparative quantitative and qualitative analysis of the results of the experimental work showed an increase in the level of formation of information culture of the respondents in the experimental group. It was revealed that in the experimental group, there were significant positive changes in the redistribution of the levels of formation of information 
culture of future teachers. Thus, the number of students who have a high level of information culture formation has significantly increased from $11.77 \%$ of respondents when ascertaining to $29.4 \%$ of students during a control examination. The number of respondents who were at the average level changed from $57.19 \%$ of future teachers of an educational organization before the start of training to $60.35 \%$ of respondents after completing it. The number of future teachers with a low level of information culture formation has significantly decreased: from $31.04 \%$ of students in an ascertaining study to $10.25 \%$ of future teachers after a formative experiment. The control group also showed positive changes, albeit less significant. The number of students with high (from $10.72 \%$ of students upon ascertaining to $12.59 \%$ of respondents during the control survey) and average (from $57.33 \%$ of future teachers to $58.94 \%$ of students) levels of formation has increased. The number of respondents who have a low level of information culture formation has slightly decreased: from $31.95 \%$ of future teachers upon confirmation to $28.47 \%$ of respondents during a control survey. The effectiveness of the technology for the formation of the information culture of future teachers is convincingly confirmed by the statistical processing of the research results.

For a more visual presentation, the data is presented in the form of a diagram (see Figure 1).

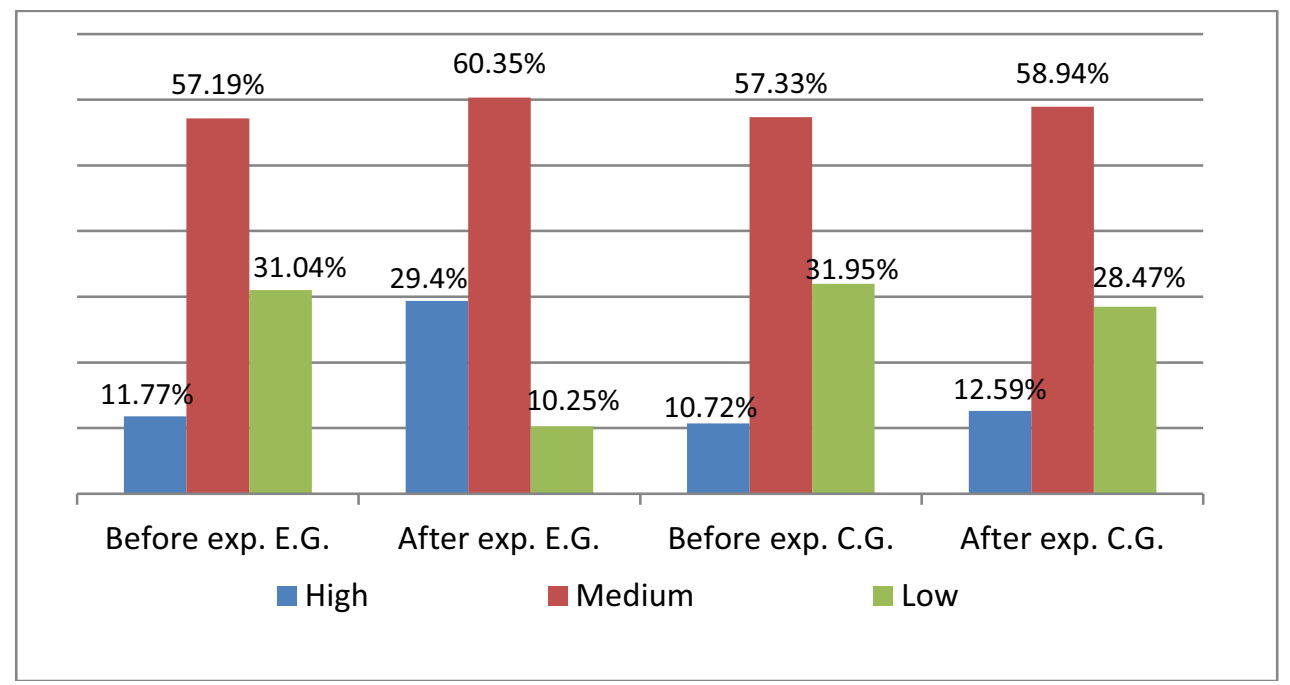

Fig. 1. Diagram of the dynamics of the formation level of information culture criteria.

Thus, a comparative analysis of the data obtained indicates the effectiveness of the formative stage of experimental work in terms of the formation of a high level of information culture of future educators, ensuring their readiness to use information technologies in professional activities.

Significant changes were noted at social levels due to an increase in the volume of information knowledge, which allows us to speak about the formation of an information thesaurus among students. As a result of lectures and practical classes, students acquired knowledge that has a positive impact on the development of the information style of thinking. In the process of solving information problems, students demonstrated the following abilities:

- the vision of the phenomenon in all the complexity of its cause-and-effect relationships;

- ability to link facts into one system;

- ability to complete the missing links of this system;

- ability to correctly interpret the received data;

- ability to correctly assess the situation and make the right decisions; 
- ability to predict the consequences of the decisions made.

With the awareness of the importance of working with information and having formed an information style of thinking, future teachers will be able to continue to independently develop their own information culture. The acquired knowledge and formed abilities made it possible to form a number of qualities in students that contribute to the improvement of their informational behavior. These qualities include:

- awareness of the need to check information for accuracy;

- the need to assess the completeness, novelty and value of information;

- awareness of the need to work with primary sources;

- critical attitude to information;

- responsibility for the creation and dissemination of information;

- understanding the possible negative consequences of the impact of information on the individual and society;

- getting rid of the habit of consuming simple, adapted information;

- adoption of norms and rules of behavior in the information environment.

The result of the formative stage of the experimental work was also an increase in the level of formation of the information culture of future teachers, which was reflected in the further development of such abilities as:

- determination of the purpose of work with information sources;

- effective use of search information systems;

- definition of the content of the document in quick view;

- extraction of information from the text, systematization and execution of the information received;

- acceptance and transmission of information;

- the use of information technology to solve professional problems.

\section{Conclusions}

Thus, the world of a modern human is saturated with various media, and this space continues to expand. Speaking about media, we mean, first of all, the entire set of information and communication tools with which each person interacts in everyday life. The era of information civilization demanded from a person new competencies of various levels, new personality traits, without which his comfortable and fruitful existence in the information environment became problematic. The formation of the information culture of teachers as a subsystem of media education has become relevant for society. At first, the dominant aspect in information education was the knowledge and skills associated with the technological development of one or another information and communication tool. Then the focus shifted to the search and analytical area. General methods that help to collect, assess, transform information turned out to be in demand. Currently, due to the fact that in the field of information technology, a sufficiently large experience has been accumulated that allows the implementation of educational functions of the media, the main task of future teachers was to master computer literacy, information competence, information culture creation and information reflection, through which the complex formation of information culture of future teachers of an educational organization.

\section{References}

1. T.P. Gordienva, N.V. Gorbunova, N.V. Smirnova, A.A. Khrulev, The use of information and telecommunication technologies in the educational process of higher education, 232 (Monograph. Humanitarian and Pedagogical Academy (branch) of the Federal State Autonomous Educational Institution of Higher Education "CFU named after V.I. Vernadsky" in Yalta, 2016) 
2. R.Yu. Hurum, Formation of information culture of a teacher, Polythematic network electronic scientific journal of the Kuban State Agrarian University,26,252-265 (2007)

3. A.A. Pankov, Formation of information culture of a teacher-musician in the conditions of functioning of a high-tech information educational environment, World of Science, Culture, Education, 6 (61), 262-265 (2016)

4. V.A. Skakunova, To the question of the concept of information and communication competence of graduates of pedagogical specialties of a language university, Higher education today,5,30-32 (2017)

5. E.A. Koshevaya,Formation of student information culture in the process of informatization of higher education, Integration of Education, 4, 243-245 (2006)

6. N. Gendina, Chapter 7 - Information Culture and Information Literacy as a Scientific Direction and a Field of Educational Activities in Russia, Editor(s): Dora Sales, María Pinto, Pathways into Information Literacy and Communities of Practice, Chandos Publishing, 167-202 (2017)

7. BiyuanXie, Construction of Teacher Culture in Applied Colleges under the Background of Educational Informationization, Microprocessors and Microsystems,336(2020)

8. V.V. Klinov, L.V. Tarasova, T.V. Dolmatova, Methodological approaches to the formation of professional and pedagogical culture of future sports teachers, Sports Science Bulletin, 1,18-22 (2018)

9. O.V. Sizov, V.A. Karnaukhova, Problems of the specificity of the formation of the musical culture of future teachers-musicians, in the context of the use of information technologies, Problems of modern teacher education,59 (4),253-256 (2018)

10. Mimi Li, Multimodal pedagogy in TESOL teacher education: Students' perspectives, System, 94, 102337 (2020)

11. B.L. Dey, D. Yen, L. Samuel, Digital consumer culture and digital acculturation, International Journal of Information Management, 51, 102057 (2020)

12. K. Patton, M. Parker, Teacher education communities of practice: More than a culture of collaboration, Teaching and Teacher Education, 67,351-360 (2017)

13. L.A. Lisavol, Experimental work as a necessary condition for the formation of information culture of a future teacher, Izvestia of the Russian State Pedagogical University. A. I. Herzen, 70(2), 92-98 (2008)

14. G.S. Vyalikova, M.A. Erofeeva, M.V. Plekhanov, Yu.A. Pluzhnikova, S.S. Saveliev,Modeling the process of formation of general pedagogical ICT competence of students on the basis of the system-activity approach. Science and Education Perspectives, 1(43), 39-56 (2020)

15. A.A. Komarov, Comparative analysis of the level of formation of information worldview of students of a pedagogical university in various areas of training, Science and Education Perspectives, 3 (39), 142-160 (2019)

16. E.P. Tatianina, Implementation of innovative processes in the formation of social research competence among future specialists in the educational environment of the university, Modern higher education: an innovative aspect,1,95-97 (2014)

17. .K.S. Aibatyrov, Z.M. Minazova, A.S. Murtuzaliev, Formation of information culture of students in the context of digitalization of education, World of science, culture, education, 6 (85),353-355 (2020)

18. Shiang-Kwei Wang, Hui-Yin Hsu, Thomas C. Reeves, Daniel C. Coster, Professional development to enhance teachers' practices in using information and communication technologies (ICTs) as cognitive tools: Lessons learned from a design-based research study, Computers \& Education, 79, 101-115 (2014) 
19. B.S. Haug, S.M. Mork, Taking 21st century skills from vision to classroom: What teachers highlight as supportive professional development in the light of new demands from educational reforms, Teaching and Teacher Education, 100, 103286 (2021)

20. M.L. Gruzdev, Formation of information culture of university students, Bulletin of Vyatka State University, 3 (2),75-77 (2019)

21. G.S. Vyalikova, M.A. Erofeeva, M.V. Plekhanov, Yu.A. Pluzhnikova, S.S. Saveliev,Modeling the process of formation of general pedagogical ICT competence of students on the basis of the system-activity approach. Science and Education Perspectives, 1 (43), 39-56 (2020)

22. M.V. Popova, Information culture of the individual as a factor of informatization of modern society, Terra Economicus,1,107-110 (2016) 